\title{
Specification of a Social Intervention Model Against COVID-19
}

\author{
Jorge Hernandez Valdes ${ }^{1 *}$, Margarita Juarez Najera', Hector Daniel Molina Ruiz ${ }^{2}$, Michiko \\ Amemiya Ramirez ${ }^{3}$, Cruz Garcia Lirios ${ }^{4}$ and Francisco Espinoza Morales ${ }^{5}$ \\ ${ }^{1}$ Department of Engineering, Metropolitan University, Mexico
}

${ }^{2}$ Department of Engineering, Hidalgo University, Mexico

${ }^{3}$ Department of Engineering, Mexico University, Mexico

${ }^{4}$ Department of Psychology, Morelos University, Mexico

${ }^{5}$ Department of Administration, Sonora University, Mexico

*Corresponding author: Jorge Hernandez Valdes, Department of Engineering, Metropolitan University, Mexico

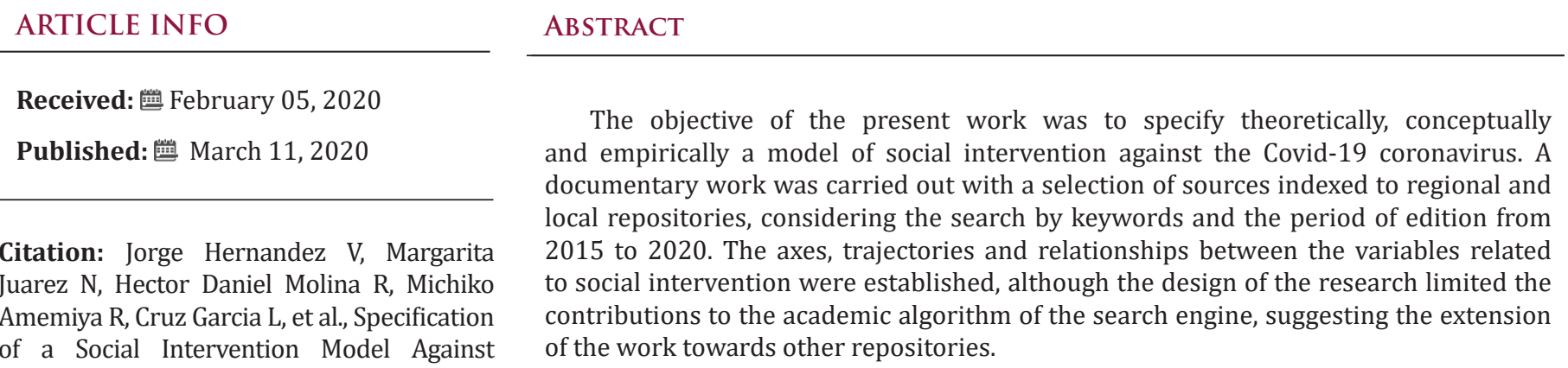
COVID-19. Biomed J Sci \& Tech Res 26(3)2020. BJSTR. MS.ID.004366.

\section{Introduction}

The infection process of Covid-19 has had two edges related to contagion when people who were infected when visiting scenarios are, or, by the visit of infected people to outbreak-free locations. In the cases of visitors to the risk areas that acquired the virus through direct contact with people involved in the outbreaks and imported this contagion to their locations that had remained without contagion, a model of social intervention explains this process and anticipates scenarios of risk [1]. Precisely, the objective of the present work is to specify a model of social intervention that explains the dynamics of contagion, as well as its prevention from the analysis of human relations, mainly labour relations, considering possible scenarios of distrust of the health authorities from the expectations, needs and resources of migrant workers in central Mexico [2]. The theoretical, conceptual and empirical frameworks for the analysis of the work scenario are exposed to a probable importation of the virus by managers who travelled to the risk areas and were exposed to the contagion of Covid-19, as well as migrant workers whose relatives work in the airport closest to the study location [3]. Next, the studies related to the interrelation between people are exposed in order to be able to establish the zones of potential risk to contagion in the research scenario, considering the forms of transmission and spread of the virus, as well as the models of social intervention [4]. A comparative study between managers, workers and family members is proposed in order to reveal the propagation scenarios of Covid-19, as well as intervention alternatives focused on confinement and mitigation, highlighting the characteristics of the migrant population with respect to the native and taking into account intervention models focused on acculturation, multiculturalism and interculturality [5]. An equation is developed for the observation and systematic recording of the interrelationships between the interested parties, as well as the processing of these data based on the 
most used statistical models in social sciences and health companies to compare samples [6]. The scenarios are discussed based on comparisons of possible cases of infection, considering the models of social intervention focused on the activity, people, groups, organizations and communities [7].

\section{Theory of Social Intervention}

From its origins, Social Work has distinguished itself by serving the infected population, developing assistance models and prevention models for health contingencies such as epidemics and pandemics developed by virus spread and contagion from person to person in the course of their interactions [8]. This is how social work in its origins developed a model of care based on home visits and the exploration of health conditions, as well as the capacities and resources of potentials infected and affected by the spread of viruses [9]. This diagnostic model focused on the sanitary conditions of the potential victims of the spread of risks served to distinguish differences and similarities between migrants and natives [10]. It was an acculture model since it was structured according to the values and norms of the hegemonic groups such as the native communities [11]. This model focused on cultural values defined social intervention in the face of risk events such as contagion due to the importation of the virus, but the exclusion of migrant communities soon forced the construction of other proposals such as multicultural and intercultural [12].

The dominant cultural values and norms of native communities imposed on migratory flows derived from containment and mitigation strategies, generating exclusion zones. It was the case of risk events such as those that occurred around the $\mathrm{H}_{1} \mathrm{~N}_{1}$ influenza in Mexico City [13]. The second model generated from the differences between the sanitary conditions of native communities regarding migrant flows, would be linked to mitigation because it recognizes the interrelation as necessary in the groups [14]. In multicultural citizens, native communities depend on the services provided by migrant flows and are willing to accept or tolerate the precedence of workers who, due to their condition and function, are exposed to potential risks, if they comply with the labor law or code civil current [15]. The cases of containment of the propagation implemented in multicultural cities with a preteen of migratory flows, native groups and native communities exemplify this multicultural model in which social intervention is separated from opportunism and moves towards the optimization of resources [16]. However both the cultural and multicultural model inhibit the initiatives of the public and social sectors around risk prevention [17]. It is the intercultural model that has allowed a dialogue between the parties, focusing on the negotiation, agreements and co-responsibilities between migratory flows and native communities [18]. While the acultural and multicultural models are structured based on biomedical management and media dissemination of prevention, care or monitoring measures of Covid-19, the intercultural model seeks proportional representation of the parties involved [19].

\section{Studies of Social Intervention}

Studies related to social intervention refer to the diagnosis of a problem in relation to alternative solutions, although the proposals are increasingly dynamic depending on the evolution of the problems [20]. In the case of the Covid-19 coronavirus spread, it has been consolidated in China, although the containment strategy has slowed the number of cases [21]. The works built from the a cultural model have proven effective in the spread of diseases such as Mexico with $\mathrm{H}_{1} \mathrm{~N}_{1}$ influenza and China with Covid-19 coronavirus, although this supposes a suppression of services and the diversification of the supply of products in digital protocols out of reach of native or marginalized communities [22]. In the case of the multicultural model in which mitigation strategies are activated based on the dominant values and norms of exclusion, even when services are concerned, political legitimization has been generated [23]. It is about risk management based on the communication and amplification of exclusion, containment and mitigation zones according to the evolution of cases [24].

In migratory flow transit communities, acculturation and multiculturalism models explain and legitimize mitigation and containment strategies, but if these communities are in constant interrelation with migratory flows and original communities, then the intercultural model not only explains but also anticipates scenarios contagion, mitigation and containment futures [25]. The discussion publishes through a common agenda between the parties involved, as well as the representativeness in voice and vote of the migratory flows and other social sectors supposes a formative disposition of capacities and resources that distinguish the organized sectors [26]. However, acultural, multicultural and intercultural models have focused their attention on relationships between groups, communities or flows of people without considering the emergence of the spread of risks such as the Covid-19 coronavirus [27]. Therefore, it is necessary to anticipate these scenarios of risks, threats, contingencies and uncertainty in order to mitigate or cancel their effects on the social dynamics of the groups, communities or sectors involved [28].

\section{Specification a Model of Social Intervention}

From the theoretical, conceptual and empirical frameworks it is possible to delineate a model for the study of the phenomenon of propagation and diseases, considering the context of the interaction groups, as well as their interconnection values and norms in a work environment such as Central Mexico where migrants, natives and natives cohabit [29]. Are there significant differences between the groups involved about the prevention of the transmission of Covid19 coronavirus in a labor scenario of migrants and natives in central Mexico? Null hypothesis. There will be significant differences between the preventive styles of the groups regarding the spread by covirus-19 coronavirus infection in a migrant and native work environment. 


\section{Method}

A documentary study was carried out with a selection of sources indexed to local and regional repositories, considering the impact factor, the edition from 2015 to 2020 and the search by keywords: "mitigation", "detection", "cancellation" and "coronavirus ". A search of the information was carried out in the local and regional repositories; Academia, Copernicus, Dialnet, Lat index, Pub index, Readlyn, Scielo, Zotero and Zenodo. Judges experts in the field selected the summaries considering the report of studies related to the spread of the coronavirus, the risk scenarios and the mitigation or cancellation policies of the person-to-person contagion. From the equation of the expansion and propagation of cases, the risk thresholds were established in the decision to implement a model according to the increase in contagions.

$$
e^{x}=1+\frac{x}{1 !}+\frac{x^{2}}{2 !}+\frac{x^{3}}{3 !}+\cdots,-\infty<x<\infty
$$

The total of selected summaries was analysed, considering public and community health strategies against contingencies, case increase and the spread of coronavirus. The experts rated 1 those summaries that offered information on the acculture models, indicated by the suppression of entertainment services and the intensification of the public health service; 2 for propagation mitigation strategies, assuming that the concentration of people would allow the proliferation of infections and, as a result of this increase, the intensification of health services in diagnosis, quarantine and treatment; 3 for the preventive measures of risks associated with the local uses and customs of festivity, recreation and entertainment, as well as the population density rate and the interrelation between groups. The data were processed in the analysis package for social sciences version 25.0 estimating the parameters of percentages, contingencies and proportions of probability of decision making associated with permissible risks or thresholds of tolerance to exposure to infections as an effect of the measures of mitigation or cancellation of the spread.

\section{Results}

The procedures of summaries that accounted for the acultural (65\%) model were superior to the findings reported around multicultural $(30 \%)$ and intercultural (5\%) models according to the findings of the experts in the field. This indicates the prevalence of a model focused on the restriction of freedoms as an instrument for canceling the spread, being observable in the case of $\mathrm{H}_{1} \mathrm{~N}_{1}$ influenza in Mexico City and containment in China with the Covid-19 coronavirus.

Regarding the differences between these models with respect to the social and public sectors, it is necessary to consider that there are significant differences between the native groups with respect to migrants in the acultural framework $\left[\mathrm{x}^{2}=15,46\right.$ (23 df) $\left.\mathrm{p}<, 05\right]$, but these differences are no longer observed in the intercultural model $\left[x^{2}=18,21(10 \mathrm{df}) \mathrm{p}>0,5\right]$. These results suggest the im- plementation of acultural models as antecedents to intercultural models since the coping with a contingency or spread of diseases has been developed since the competition of the interested parties. Regarding the proportions of probabilities at the time of deciding the choice of an intervention model against a contingency, its actors and resources reported in the updated and specialized literature, tolerance thresholds are observed only in the acultural [OR = $18,20815,20$ to 26,21 )] model and not so in the multicultural [OR $=19,21(13,21$ to 18,21$]$ and intercultural $[\mathrm{OR}=17,21(13,21$ to $17,20)]$ models.

\section{Discussion}

The contribution of this work to the state of the art lies in the specification of a diagnosis, design and implementation of a model of social intervention focused on local actors, sectors and communities involved in the possible spread of Covid-19 coronavirus in central Mexico. From the theoretical, conceptual and empirical frameworks, as well as the results found, it is possible to note that the acultural model is a precedent of the intercultural model, being the transitional multicultural model. This is so because health contingencies such as the spread of diseases present substantial increases that must be mitigated or reduced to their minimum expression and then establish a training of the actors in the prevention of risk scenarios. Studies that reported the hegemony of the spread containment model warn of tolerable and permissible minimum risk thresholds. In the present work a range of homogeneous random effects of the acultural model has been established, suggesting its relevance before the onset of a contingency. Research lines concerning social interventions will allow us to see the effectiveness of this model in which services are suppressed and traffic flows are controlled to inhibit contagion.

\section{Conclusion}

The objective of the present work was to specify theoretically, conceptually and empirically a model for the study of the probable spread of the coronavirus in a local scenario of migratory flows, native peoples and native communities of central Mexico. However, the lack of studies related to the implementation of a multicultural and intercultural model suggests the extension of work towards the analysis of tolerance and representative scenarios between social sectors and communities. Research lines related to diagnoses, design and implementation of models, considering the type of cultural relationship between natives and migrants will allow to anticipate scenarios of contagion and mitigation of cases, considering values and norms, resources and dialogue capacities between the actors, agreements between the parties and co-responsibility between those who make decisions and those who carry them out.

\section{References}

1. Aldana W (2019) Governance of health responsibility in a town in central Mexico. Nur Emp 19(33): 5-17. 
1. Aldana W (2019) Specification a model for study of migration identity. J Psi Hum 30(1): 1-8.

2. Anguiano F (2018) Exploratory factor structure of an attitude scale towards groups close to HIV / AIDS carriers. J Lim 13(42): 61-74.

3. Bermudez G (2019) Contrasting a confirmatory model for study of workplace harassment in public health professional networks and environments. Sal Tra 7(2): 121-132.

4. Bustos J (2019) Expectations towards policies for terminating pregnancy in immigrants from the state of Mexico. Inv 2 14(3): 24-33.

5. Carreon (2019) J Algorithmic meta-analysis of the effects of social services on the vulnerable population. J Geo Env ear Sci Int 22(1): 1-9.

6. Carreon J (2019) Exploratory factorial structure of the intention to emigrate. Soc Work 87(2): 57-64.

7. Carreon J (2019) Studies of common goods and governance of resources. J Adi Med \& Ter 6(1): 13-23.

8. Espinoza F (2019) Governance of migratory flows from establishement of identitiy and agenda of occupational health. J Hue Mig 4(7): 139-171.

9. Garcia C (2019) Exploratory dimension of attitude toward occupational health. Dim Emp 17(3): 1-8.

10. Garcia C (2019) Governance of digital labor of interculturalism in millennials. J Stu Res 4 (1): 47-54.

11. Garcia C (2017) Limits two models of occupational health in a study of adherence to asthma treatment in elderly migrant workers. J Vis Ger 146(1): 103-118.

12. Garcia C (2019) Reflective factor structure of occupational health governance. J Sum 7 (2): 1-17.

13. Garcia C (2019) Specification a model for study of biopolitics. J Est Soc 20(43): 128-135.

14. Garcia C (2020) Specification a model for study of occupational health. Glo J Man \& Bus Res 20(1): 1-6.

\section{ISSN: 2574-1241}

DOI: $10.26717 /$ BJSTR.2020.26.004366

Jorge Hernandez Valdes. Biomed J Sci \& Tech Res

(c) (P) This work is licensed under Creative

Submission Link: https://biomedres.us/submit-manuscript.php
15. Garcia C (2020) Specification a model for study of policies risk. Int J Res Hum Soc Stu 7(2): 1-10.

16. Garcia C Specification a model of positivity intervention. J Soc Sci Hum Res 4 (11): 1-9.

17. Garcia C (2019) Specification of self-care model. Luz med 42 (1): 15-25.

18. Garcia C (2018) Structure of perception in public safety crisis. Lib 18 (1): 37-44.

19. Garcia J (2018) Reliability and validity of an instrument that measures health welfare. Eur 15(2): 244-252

20. Juarez M (2017) reliability and validity of an instrument that measures dimensions of security and risk perception in students of a public university. Int J Adv Soc Sci Hum 11(12): 1-23.

21. Juarez M (2020) Specification a model for study of corporate assistance. Glo J Arc \& Ant 11 (2): 50-54.

22. Llamas B (2019) Specification a model of adherence to treatment. Aja 17 (1): 140-160.

23. Martinez E (2019) Governance of quality of life and wellbeing subjective. Aja 17(1): 121-139.

24. Morales M (2018) Self-care model and prevention risk associated with human papilloma vuirus in a public university located in central Mexico. J Sal Pub Ins 14(27): 17-25.

25. Moreno E (2019) Governance of social representations of quality of life. Psy Res Int J 4(5): 1-5.

26. Quintero M (2018) Evaluation of a model of institutional strategies of self-care condom use and prevention in university students. J Sal Pro 12(23): 56-68.

27. Quiroz C Metanalytical retrospective of the policies in the handling of risk of transportation in the Mexico City. Net J Soc Sci 7(4): 92-100.

28. Sandoval F (2019) Structure categorial exploratory of entropy and negentropy agenda setting migratory. J Ele Psy Pol 17(43): 94-107.

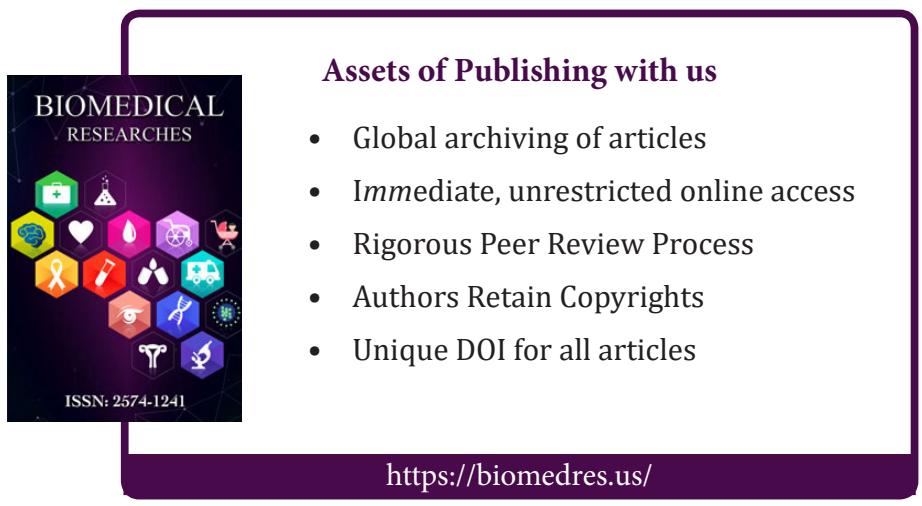

